\title{
Solution structure of the parvulin-type PPlase domain of Staphylococcus aureus PrsA - Implications for the catalytic mechanism of parvulins
}

\author{
Outi Heikkinen ${ }^{1}$, Raili Seppala², Helena Tossavainen ${ }^{2}$, Sami Heikkinen ${ }^{1}$, \\ Harri Koskela ${ }^{3}$, Perttu Permi*2 and Ilkka Kilpeläinen*1
}

Address: ${ }^{1}$ Laboratory of Organic Chemistry, Department of Chemistry, P.O. Box 55, FI-00014 University of Helsinki, Finland, ${ }^{2}$ Program in Structural Biology and Biophysics, Institute of Biotechnology, P.O. Box 65, FI-00014 University of Helsinki, Finland and ${ }^{3}$ Finnish Institute for Verification of the Chemical Weapons Convention, P.O. Box 55, FI-00014 University of Helsinki, Finland

Email: Outi Heikkinen - outi.k.heikkinen@helsinki.fi; Raili Seppala - raili.seppala-lehto@ helsinki.fi; Helena Tossavainen - helena.tossavainen@helsinki.fi; Sami Heikkinen - sami.heikkinen@helsinki.fi; Harri Koskela - harri.t.koskela@helsinki.fi; Perttu Permi* - perttu.permi@helsinki.fi; Ilkka Kilpeläinen* - ilkka.kilpelainen@helsinki.fi

* Corresponding authors

Published: 24 March 2009

BMC Structural Biology 2009, 9:17 doi:10.1 186/1472-6807-9-17

This article is available from: http://www.biomedcentral.com/1472-6807/9/17

(C) 2009 Heikkinen et al; licensee BioMed Central Ltd.

This is an Open Access article distributed under the terms of the Creative Commons Attribution License (http://creativecommons.org/licenses/by/2.0), which permits unrestricted use, distribution, and reproduction in any medium, provided the original work is properly cited.

\begin{abstract}
Background: Staphylococcus aureus is a Gram-positive pathogenic bacterium causing many kinds of infections from mild respiratory tract infections to life-threatening states as sepsis. Recent emergence of $S$. aureus strains resistant to numerous antibiotics has created a need for new antimicrobial agents and novel drug targets. S. aureus PrsA is a membrane associated extracytoplasmic lipoprotein which contains a parvulin-type peptidyl-prolyl cis-trans isomerase domain. $\operatorname{Prs} \mathrm{A}$ is known to act as an essential folding factor for secreted proteins in Gram-positive bacteria and thus it is a potential target for antimicrobial drugs against $S$. aureus.
\end{abstract}

Results: We have solved a high-resolution solution structure of the parvulin-type peptidyl-prolyl cis-trans isomerase domain of S. aureus PrsA (PrsA-PPlase). The results of substrate peptide titrations pinpoint the active site and demonstrate the substrate preference of the enzyme. With detailed NMR spectroscopic investigation of the orientation and tautomeric state of the active site histidines we are able to give further insight into the structure of the catalytic site. NMR relaxation analysis gives information on the dynamic behaviour of PrsA-PPlase.

Conclusion: Detailed structural description of the $S$. aureus PrsA-PPlase lays the foundation for structure-based design of enzyme inhibitors. The structure resembles hPin I-type parvulins both structurally and regarding substrate preference. Even though a wealth of structural data is available on parvulins, the catalytic mechanism has yet to be resolved. The structure of $S$. aureus PrsA-PPlase and our findings on the role of the conserved active site histidines help in designing further experiments to solve the detailed catalytic mechanism. 


\section{Background}

Staphylococcus aureus is a Gram-positive bacterium causing many kinds of infections from mild respiratory tract infections to life-threatening states as sepsis. It produces many toxins and has a remarkable ability to acquire resistance to antimicrobial drugs. Many S. aureus strains have acquired resistance to commonly used antibiotics and some strains are becoming multi-resistant. Methicillin-resistant strain of Staphylococcus aureus (MRSA) is the principal cause of severe nosocomial infections which can be fatal to compromised patients. Whole genome sequencing of two MRSA strains in 2001 was regarded as a way to find targets for novel antibiotics against infections caused by MRSA [1].

PrsA protein is found ubiquitously in Gram-positive bacteria, including S. aureus [Swiss-Prot:P60747], but not in Gram-negative ones [2,3]. By sequence homology PrsA contains a parvulin-type peptidyl-prolyl cis-trans isomerase (PPIase) domain and flanking $\mathrm{N}$ - and C-terminal domains. PPIases are enzymes that catalyze cis-transisomerization of the peptide bonds preceding proline residues [4]. Biological role of PPIases is to act as chaperones or foldases in protein folding and remodelling. FK506 binding proteins (FKBPs), cyclophilins and parvulins form the three classes of PPIases each having their own fold, substrate specificity and catalytic mechanism.

PrsA is localized at the space between plasma membrane and cell wall and it is bound to the cell membrane through a lipid-anchor attached to the N-terminal cysteine residue $[2,3]$. It has been shown to have a role as folding catalyst of secreted proteins. In bacteria, secreted proteins include enzymes important for formation of the cell wall and toxins. Due to importance of the catalyzed reaction in protein folding PrsA is a potential target for novel antimicrobial drugs. PrsA has been previously shown to be an essential protein for viability of $B$. subtilis [2].

Parvulin-type PPIases are 100 residues long globular protein domains folding into a four-stranded antiparallel $\beta$-sheet core surrounded by four $\alpha$-helices $(\beta \alpha 3 \beta \alpha \beta 2$ parvulin-fold) [4]. Parvulin-type PPIases have been found both in bacteria and in eukaryotes. At present there are structures of 7 different parvulins available in the Protein Data Bank: human Pin1 (e.g. [PDB: 1 PIN, $\underline{1 \mathrm{NMV}}$ and 1NMW]) [5,6] and Par14 [PDB:1EQ3][7], Pin1At from Arabidopsis thaliana [PDB:1J6Y][8], Par10 [PDB:1JNS] [9] and SurA [PDB:1M5Y] [10] from Escherichia coli, Ess1 from Candida albicans [PDB:1YW5][11] and PrsA-PPIase from Bacillus subtilis [PDB:1ZK6][12]. Also several other parvulin-type PPIases are known, e.g. Par27 from Bordetella pertussis [13], but their structures are still to be solved. The subtypes of parvulins differ in length and composition of the $\mathrm{S}_{1}-\mathrm{H}_{1}$ loop. In hPin1-type parvulins the loop has a high number of positively charged residues and this is thought to induce the preference for substrates having a negatively charged residue, preferably a phosphorylated serine/threonine, before the processed proline [5]. In Par14-type parvulins this loop is missing and in SurA PPIase domain $\mathrm{I}$ the $\mathrm{S}_{1}-\mathrm{H}_{1}$ loop contains mainly hydrophobic residues $[7,10]$.

PrsA of S. aureus shows 24\% amino acid sequence conservation to PrsA protein from Bacillus subtilis [SwissProt:P24327]. The PPIase domain is the most conserved area of the sequence ( $42 \%$ of the residues conserved). Sequence comparison of B. subtilis and $S$. aureus PrsA-PPIases shows that they differ in length and nature of the $S_{1}$ $\mathrm{H}_{1}$ loop. S. aureus PrsA-PPIase contains a long loop rich of lysine residues whereas in $B$. subtilis PrsA the loop is very short. This suggests that the structure and the substrate specificity of $S$. aureus PrsA-PPIase would rather resemble hPin1-type parvulins than B. subtilis PrsA-PPIase.

Since PrsA is known to be an essential protein for other gram-positive bacteria [2] it is a potential target for antimicrobial drugs against $S$. aureus infections. Exact knowledge of the structure and catalysis mechanism of PrsAPPIase is a prerequisite for successful design of efficient and selective enzyme inhibitors to be used as antibacterial agents against Gram-positive bacteria. We have studied structure and function of the parvulin-type PrsA-PPIase from $S$. aureus using NMR spectroscopy.

\section{Results}

\section{Protease-coupled PPlase assay}

The results of protease-coupled PPIase assay confirm the prolyl isomerase activity of $S$. aureus PrsA-PPIase (Figure $1)$. The highest catalytic activity $\left(\mathrm{k}_{\mathrm{cat}} / \mathrm{K}_{\mathrm{m}}=33 \mathrm{mM}^{-1} \mathrm{~s}^{-1}\right)$ was observed with Suc-AEPF- $p$ NA peptide. Comparison with the results obtained with PrsA-PPIase from B. subtilis indicates difference in the substrate preference. The enzyme from $S$. aureus prefers a substrate having a negatively charged residue before the proline residue (preferred substrate Suc-AEPF- $p$ NA). The same enzyme from B. subtilis has the highest catalytic activity towards Suc-AKPF- $p$ NA peptide.

\section{Structure determination}

${ }^{1} \mathrm{H}-{ }^{15} \mathrm{~N}-\mathrm{HSQC}$ spectrum of PrsA-PPIase (Figure 2) shows clearly resolved signals of a well-folded protein. However, there is a second set of signals with about one fifth of intensity of the main signals. Despite attempts to change the sample conditions and the protein construct we were unable to remove this extra set of signals from the ${ }^{1} \mathrm{H}-15 \mathrm{~N}$ HSQC spectrum. Both SDS-PAGE analysis and mass spectra indicate that there is only one kind of polypeptide present in the sample. Narrow distribution of the ${ }^{1} \mathrm{H}$ chemical shifts of the minor signals implies that they originate from an unstructured polypeptide. A closer inspec- 


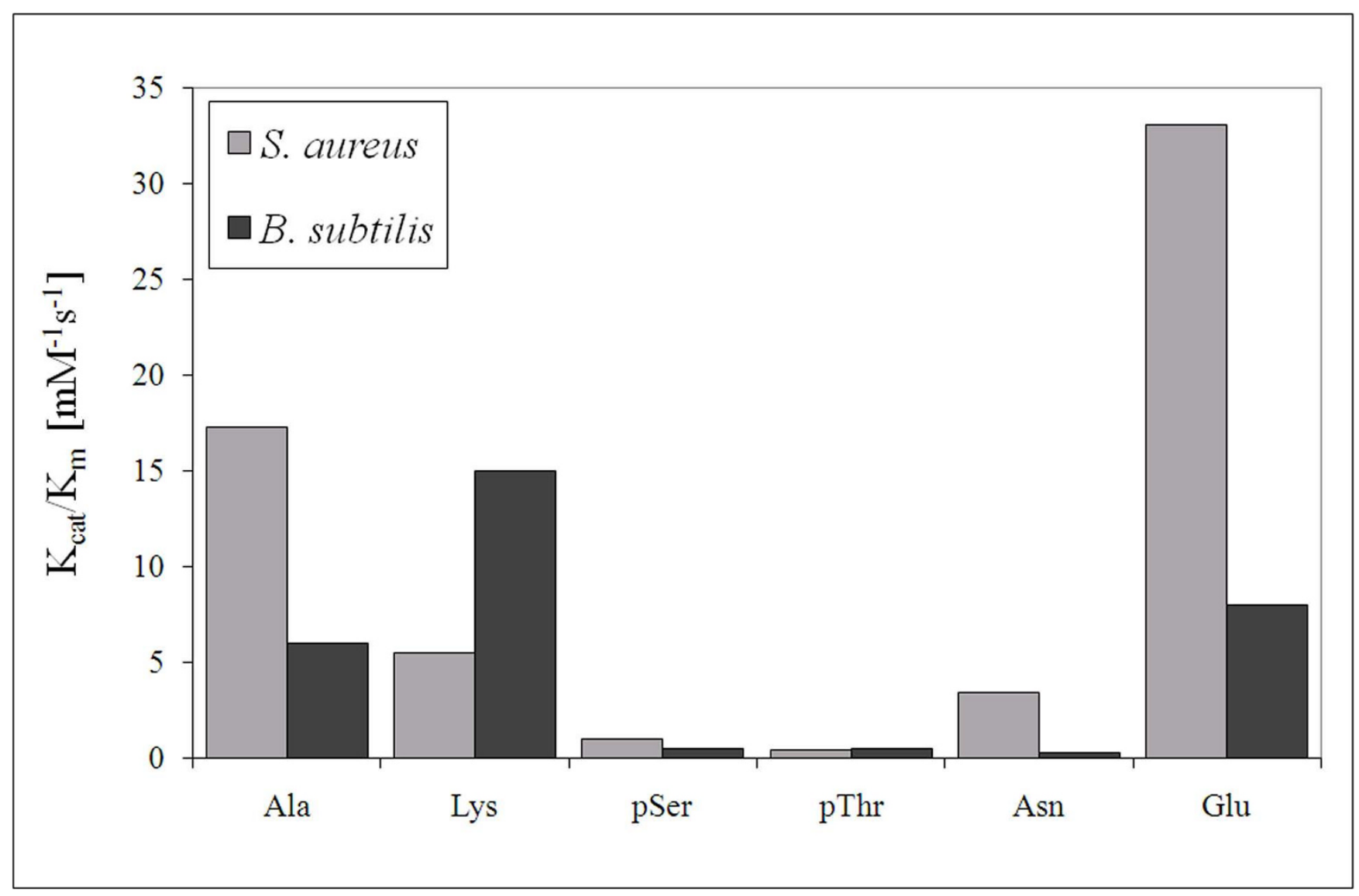

Figure I

Protease-coupled PPlase assay. Catalytic activity of S. aureus and B. subtilis PrsAs towards Suc-AXPF-pNA tetrapeptides, where $X=A, K, p S, p T, N$ or $E$.

tion of the NOESY spectra showed that these resonances have practically no NOEs. From this we concluded that the extra signals belong to an unfolded form of PrsA-PPIase which probably would not interfere with the structure determination and we proceeded with this sample. Sequential assignment of the extra signals (data not shown) indeed confirmed they originate from the same polypeptide sequence as the main signals.

All backbone amide signals except K155 are visible in the ${ }^{1} \mathrm{H}-{ }^{15} \mathrm{~N}-\mathrm{HSQC}$ spectrum and were sequentially assigned. Assignments were found for $97 \%$ of all ${ }^{1} \mathrm{H}-,{ }^{13} \mathrm{C}$ - and ${ }^{15} \mathrm{~N}$ resonances. Majority of the missing assignments belong to the overlapping side chain resonances of numerous lysine residues. Peak picking of the three-dimensional ${ }^{13} \mathrm{C}$ - and 15N-edited NOESY-HSQC spectra yielded 2621 and 1242 cross-signals, respectively. Total of 2161 distance restraints were extracted from the NOESY spectra with the automatic NOESY signal assignment and torsion angle dynamics procedure of CYANA 2.1 software [14]. After the final molecular dynamics refinement with AMBER program [15] 25 structures were chosen to the representative structure family. The final set of structures contains neither distance restraint violations over $0.2 \AA$ nor dihedral angle restraint violations exceeding $7^{\circ}$. According to the structure statistics (Table 1 ) and the quality analysis with PROCHECK-NMR [16] and WHAT_CHECK [17] the structure determination yielded a structure family of excellent quality. RMSD between the structures (residues 140-243) is $0.5 \AA$ for the backbone and $1.0 \AA$ for all the heavy atoms. If the somewhat less ordered residues of the $\mathrm{S}_{1}-\mathrm{H}_{1}$ loop (residues 153-159) are excluded, RMSD drops to $0.3 \AA$ and $0.8 \AA$ for the backbone and heavy atoms, respectively. Over $99 \%$ of the residues reside on the favoured regions of the Ramachandran plot.

Since there is a distracting difference in the orientation of the two conserved active site histidines between the crystal $[5,10,11]$ and the solution $[6-9,12]$ structures of parvulin PPIases, we decided to look into the construction of the active site of the enzyme more closely. The results of protonation and tautomeric state determination of the active site histidines (see ref. [18] for interpretation of the results) are represented in Figure 3. Due to partially over- 


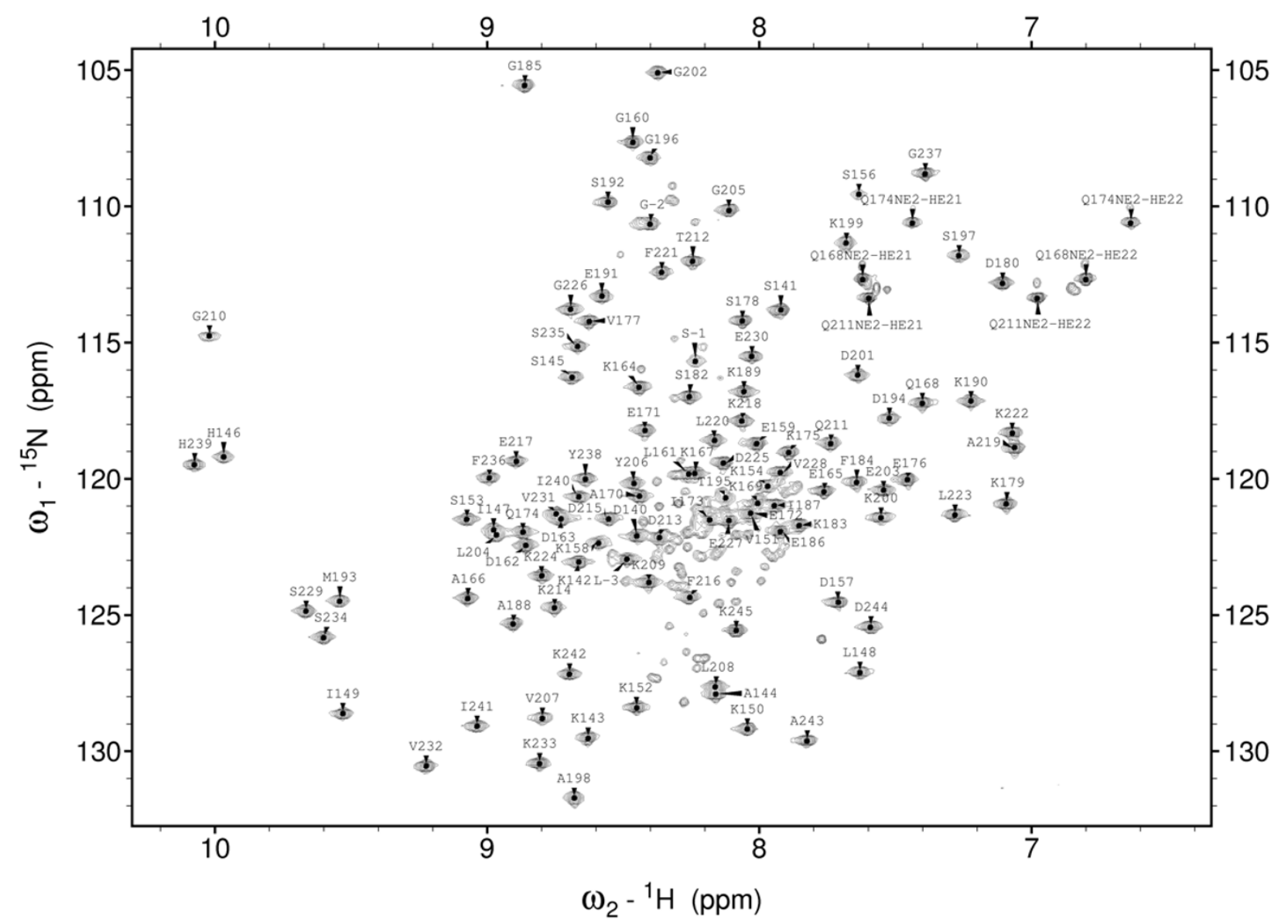

Figure 2

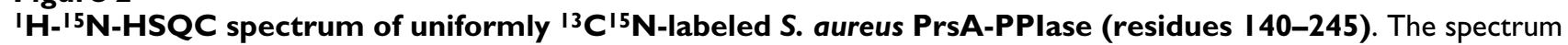
was recorded at $800 \mathrm{MHz}$ field at $25^{\circ} \mathrm{C}$. The protein concentration was $\sim \mathrm{mM}$ and sample buffer was $20 \mathrm{mM}$ Bis-Tris, $\mathrm{pH} 6.8$. Resonance assignments of backbone and side chain amides are shown on each peak.

lapping $\mathrm{H} 146$ and $\mathrm{H} 239 \mathrm{H}_{2}-\mathrm{C}_{2}$ signals the protonation state determination yielded only an average value of the two residues for peptide-unbound form of PrsA-PPIase. Based on the average value one can judge that the histidines are in deprotonated state. The Suc-AEPF-pNA titration however separated the two $\mathrm{H}_{2}-\mathrm{C}_{2}$ signals and enabled separate determination of the protonation states. Protonation state and tautomeric state of the active site histidines were not affected by the presence of substrate peptide Suc-AEPF-pNA. Both H146 and H239 are in deprotonated state but they differ in tautomeric state of the side chain. $\mathrm{H} 146$ is in $\mathrm{N}_{3}$-protonated state whereas $\mathrm{H} 239$ binds the proton through $\mathrm{N}_{1}$ (see Figure 3 ). Also the $\mathrm{C}_{4}$ chemical shifts of the histidines support this conclusion [19].

\section{Structure description}

Structure of PrsA-PPIase (Figure 4) is a typical parvulinfold consisting of a four-stranded antiparallel $\beta$-sheet core $\left(\mathrm{S}_{1}, \mathrm{~S}_{2}, \mathrm{~S}_{3}\right.$ and $\left.\mathrm{S}_{4}\right)$ and four $\alpha$-helices $\left(\mathrm{H}_{1}, \mathrm{H}_{2}, \mathrm{H}_{3}\right.$ and $\left.\mathrm{H}_{4}\right)$ surrounding it. PrsA-PPIase has a ten-residue extended loop containing four positively charged lysine residues (K152, K154, K155 and K158) between $S_{1}$ and $H_{1}$. This loop is more loosely defined compared with the rest of the structure, and it lacks regular secondary structure. The hydrophobic core of the protein on the concave side of the $\beta$-sheet is formed by L204, V207, F216, L220 and I241 and by the two histidines (H146 and H239) occupying the active site. On the convex side of the $\beta$-sheet the main hydrophobic residues attaching the helices $\mathrm{H}_{1}$ and $\mathrm{H}_{2}$ are I147, V177, F184, V228 and I240. The antiparallel orientation of the active site histidine ring planes brings the $\mathrm{N}_{1}$ nitrogens next to each other (Figure 5). The differing tautomeric state of the two histidines enables a hydrogen bond to be formed between the histidine rings.

\section{Peptide titrations}

Location of the active site and structural changes during enzyme action were probed by titration experiments with proline containing tetrapeptides previously shown to be substrates for parvulin PPIases [20]. Titration of PrsA-PPIase with Suc-AXPF- $p$ NA $(X=A, K$ or E) substrate peptides 
Table I: Structure statistics of PrsA-PPlase

\begin{tabular}{|c|c|}
\hline Total distance restraints & 2161 \\
\hline Short-range $|\mathrm{i}-\mathrm{j}| \leq \mathrm{I}$ & 1081 \\
\hline Medium-range, $|<| i-j \mid<5$ & 379 \\
\hline Long-range, $|i-j| \geq 5$ & 764 \\
\hline Restraints per residue & 19.5 \\
\hline \multicolumn{2}{|l|}{ Violation statistics } \\
\hline Maximum NOE restraint violation $(\AA ̊)$ & 0.16 \\
\hline Number of NOE violations $>0.10 \AA$ & $3 \pm 2$ \\
\hline \multicolumn{2}{|l|}{ Energies } \\
\hline Average restraint violation energy $(\mathrm{kcal} / \mathrm{mol} \pm \mathrm{SD})$ & $9.55 \pm 0.86$ \\
\hline Average AMBER energy $(\mathrm{kcal} / \mathrm{mol} \pm \mathrm{SD})$ & $-3259.69 \pm 8.55$ \\
\hline \multicolumn{2}{|l|}{ RMS deviations from ideal covalent geometry } \\
\hline Bond lengths $(\AA \pm S D)$ & $0.0096 \pm 0.0001$ \\
\hline Bond angles $\left({ }^{\circ} \pm \mathrm{SD}\right)$ & $1.93 \pm 0.02$ \\
\hline \multicolumn{2}{|c|}{ Atomic coordinate RMSD $(\AA \pm$ SD) for residues $140-243$ and $(140-152,160-243)$} \\
\hline Backbone atoms & $0.55 \pm 0.18(0.31 \pm 0.05)$ \\
\hline Heavy atoms & $1.07 \pm 0.20(0.80 \pm 0.06)$ \\
\hline \multicolumn{2}{|l|}{ Ramachandran map regions (\%) } \\
\hline Residues in most favoured regions & 93.9 \\
\hline Additionally allowed regions & 5.9 \\
\hline Generously allowed regions & 0.2 \\
\hline Disallowed regions & 0.0 \\
\hline
\end{tabular}

induced chemical shift perturbations in the ${ }^{1} \mathrm{H}-{ }^{15} \mathrm{~N}-\mathrm{HSQC}$ spectrum. However, large excess of peptide was needed in all three cases in order to achieve clear changes in the spectrum. The binding affinity of the peptides was in millimolar range (data not shown). Largest chemical shift perturbations were observed at helix $\mathrm{H}_{3}$, strand $\mathrm{S}_{2}$ and at $\mathrm{S}_{2}-\mathrm{H}_{4}$ and $\mathrm{S}_{3}-\mathrm{S}_{4}$ loops which reflects the typical substrate binding site of parvulins (Figure 6) [5]. Upon titration with the Suc-AEPF-pNA peptide chemical shift changes were observed also at the $\mathrm{S}_{1}-\mathrm{H}_{1}$ loop. This behaviour was not observed with other peptides used. The $\mathrm{S}_{1}-\mathrm{H}_{1}$ loop contains a cluster of positively charged lysines which presumably participate in binding of the negatively charged glutamate side chain of the substrate. During Suc-AEPF$p$ NA titration chemical shift changes of the aromatic side chains were also followed using ${ }^{1} \mathrm{H}-{ }^{13} \mathrm{C}-\mathrm{HSQC}$ spectrum. $\mathrm{H}_{2}$ proton resonances of the both active site histidines moved about 0.5 ppm upfield (see Figure 3) which reflects a close proximity to the peptide binding site.

\section{Dynamics and exchange}

The dynamical behaviour of the protein was depicted through generalized order parameter $S^{2}$, which was extracted from $R_{1}$ and $R_{2}$ relaxation rates and heteronuclear NOEs of the backbone amides. Additional information on dynamics was gained through backbone amide exchange rates. The generalized order parameters and the exchange rates were determined both in presence and in absence of the Suc-AEPF-pNA peptide substrate. The data for K155 and S156 and the relaxation data for D140 are missing due to low intensity of the ${ }^{1} \mathrm{H}-{ }^{15} \mathrm{~N}-\mathrm{HSQC}$ signals, and the data for V151 and E172 are missing due to signal overlap. The relaxation analysis was successfully applied for all the residues containing complete set of relaxation data. Graph of generalized order parameter $S^{2}$ as function of sequence (Figure 7a) shows an overall $\mathrm{S}^{2}$ of about 0.8 and a consistent decrease at the $\mathrm{S}_{1}-\mathrm{H}_{1}$ loop. Presence of Suc-AEPF-pNA peptide induced changes in the order parameter at the loops surrounding the active site but also at the $\mathrm{H}_{1}$ helix (Figure $7 \mathrm{~b}$ ). The backbone amide proton exchange rates are slow within the secondary structure elements and the regions of faster exchange reflect the dynamical behaviour of the protein demonstrated by the order parameters (Figure 7c). The fastest exchange rates are observed for residues at the $\mathrm{S}_{1}-\mathrm{H}_{1}$ loop and at the loops facing the active site cavity.

\section{Discussion}

In this study we have investigated the structure and function of the parvulin-type PPIase domain of PrsA protein from $S$. aureus. NMR spectroscopic structure determination of PrsA-PPIase yielded a high-quality structure which enabled investigation of the catalytic site in detail. Solution structure of PrsA-PPIase shows close structural similarity to hPin1-type parvulins but also some important differences in constitution of the active site. The original hypothesis on the catalysis mechanism of the parvulintype PPIases is based on the crystal structure of hPin 1 [5]. However, the recent studies of hPin 1 [21-23] have provided new insight into the functional status of the active 


\begin{tabular}{|c|c|c|c|c|c|c|c|c|c|}
\hline \multirow[t]{2}{*}{ Residue } & \multicolumn{2}{|c|}{$\begin{array}{c}\text { Chemical } \\
\text { Shift } \\
\text { (ppm) }\end{array}$} & \multirow[t]{2}{*}{$\begin{array}{c}\mathrm{I} / \mathrm{I}_{0} \\
\left(\mathrm{C}_{2}-\mathrm{H}\right)\end{array}$} & \multirow[t]{2}{*}{$\begin{array}{c}\text { Protonation } \\
\text { state }\end{array}$} & \multicolumn{2}{|c|}{$\begin{array}{c}\text { Chemical } \\
\text { Shift } \\
\text { (ppm) }\end{array}$} & \multirow[t]{2}{*}{$\begin{array}{c}\mathrm{I} / \mathrm{I}_{0} \\
\left(\mathrm{C}_{4}-\mathrm{H}\right)\end{array}$} & \multirow[t]{2}{*}{$\begin{array}{c}\text { Tautomeric } \\
\text { state }\end{array}$} & \multirow[t]{2}{*}{$\begin{array}{l}\text { Histidine } \\
\text { structure }\end{array}$} \\
\hline & $C_{2}$ & $\mathrm{H}_{2}$ & & & $C_{4}$ & $\mathrm{H}_{4}$ & & & \\
\hline \multicolumn{10}{|c|}{ Without substrate } \\
\hline H146 & \multirow{2}{*}{136.8} & \multirow{2}{*}{7.7} & \multirow{2}{*}{0.64} & \multirow{2}{*}{ Deprotonation } & 116.4 & 7.0 & 0.56 & $\mathbf{N}_{3}-\mathbf{H}$ & \\
\hline H239 & & & & & 130.0 & 7.1 & 0.93 & $\mathbf{N}_{1}-\mathbf{H}$ & \\
\hline \multicolumn{10}{|c|}{ With Suc-AEPF-pNA } \\
\hline H146 & 136.5 & 7.1 & 0.61 & Deprotonation & 116.6 & 7.0 & 0.61 & $\mathbf{N}_{3}-\mathbf{H}$ & \\
\hline H239 & 137.7 & 7.2 & 0.55 & Deprotonation & 130.1 & 7.1 & 0.86 & $\mathbf{N}_{1}-\mathbf{H}$ & \\
\hline
\end{tabular}

\section{Figure 3}

Determination of the tautomeric state of the active site histidines. See reference [18] for further details on interpretation of the results. Blue: Due to partially overlapping $\mathrm{H}_{2}-\mathrm{C}_{2}$ signals the protonation state determination yielded only an average value of the two peaks. The value suggests that the histidines are in deprotonated state. The Suc-AEPF-pNA titration however separated the two $\mathrm{H}_{2}-\mathrm{C}_{2}$ signals and enabled separate determination of the protonation states. Red: Unique assignment is not available, but the protonation state determination gives equivalent results for both peaks.

site residues and thus have brought the original catalysis mechanism into question. The solution structure of $S$. aureus PrsA-PPIase supports these findings but also brings out some new aspects into the debate.

The results of protease-coupled PPIase assay indeed confirm that PrsA-PPIase functions as a prolyl-isomerase. The most efficient catalysis was observed with Suc-AEPF- $p$ NA peptide. The substrate preference of $S$. aureus PrsA-PPIase resembles that of hPin 1 which was somewhat expected based on common $\mathrm{S}_{1}-\mathrm{H}_{1}$ loop rich of positively charged residues. Binding of multivalent anions to the $\mathrm{S}_{1}-\mathrm{H}_{1}$ loop of PrsA-PPIase was also confirmed by NMR titrations with sodium sulphate (data not shown). Clear chemical shift perturbations resembling the ones Bayer et al. observed with hPin 1 [6] were detected at the $\mathrm{S}_{1}-\mathrm{H}_{1}$ loop. Paradoxically, the protease-coupled PPIase assay showed practically no prolyl-isomerase activity towards Suc-A(pS/ pT)PF-pNA peptides.
The overall structure of PrsA-PPIase shows resemblance to the previously published parvulin PPIase structures. A structure similarity search with DALI program [24] gave hPin1 [PDB:1F8A] and C. albicans Ess1 [PDB:1YW5] as the two closest hits with 1.7 and $2.0 \AA$ backbone RMSDs, respectively. The $\mathrm{H}_{1}-\mathrm{S}_{1}$ loop of positively charged residues is also present in hPin 1 and Ess1. Being a potential target for anticancer drugs, the human mitotic regulator hPin 1 is the most studied parvulin. Overlay of PrsA-PPIase and the crystal structure of hPin 1 containing AlaPro dipeptide substrate [5] shown in Figure 8a indicates that the largest differences between the two structures are found at the loosely defined $\mathrm{S}_{1}-\mathrm{H}_{1}$ loop and at the $\mathrm{H}_{1}-\mathrm{H}_{2}$ loop. PrsAPPIase of $B$. subtilis lacks the extended loop between the $S_{1}$ sheet and the $\mathrm{H}_{1}$ helix. Overlay of the secondary structure elements the two PrsA-PPIases reveals the difference in the orientation and length of the $\mathrm{H}_{1}$ helix (Figure $8 \mathrm{~b}$ ). Otherwise the backbone traces of the two PrsA-PPIases are fairly similar. 


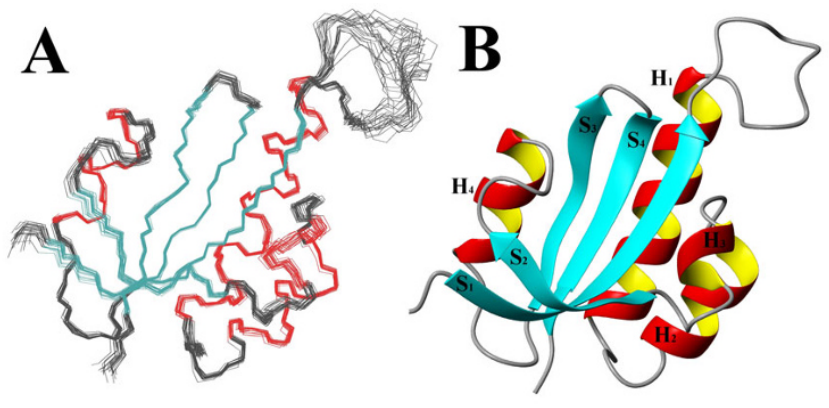

Figure 4

Solution structure of S. aureus PrsA-PPlase. The protein construct used in the study comprised residues 140-245 of the S. aureus PrsA [Swiss-Prot: P60747]. (A) Superimposed backbone traces of the 25 structures in the structure ensemble. Secondary structure elements are colour coded as: red - helix; cyan - strand; grey - coil. (B) A ribbon model of the average structure showing the codes of the secondary structure elements. Structure visualisation was done using MOLMOL [33].

The active site of PrsA-PPIase was mapped by NMR titrations with parvulin substrate peptides. Our results conform well with the previous studies with other parvulins $[5,12]$. Largest chemical shift changes occurred at $\mathrm{H}_{3}$ helix, $\mathrm{S}_{2}$ strand and at $\mathrm{S}_{2}-\mathrm{H}_{4}$ and $\mathrm{S}_{3}-\mathrm{S}_{4}$ loops which face the active site and contain the residues thought to participate in the catalysis mechanism (Figure 6). Based on the NMR titrations the dissociation constant for all tested peptides was in millimolar regime and most of the spectral changes were practically the same with all the three peptides. During the Suc-AEPF-pNA peptide titration, but not with the other peptides, we observed consistent chemical shift perturbations at the $\mathrm{S}_{1}-\mathrm{H}_{1}$ loop. Backbone amide titration data demonstrates involvement of the $\mathrm{S}_{1}-\mathrm{H}_{1}$ loop in sub-

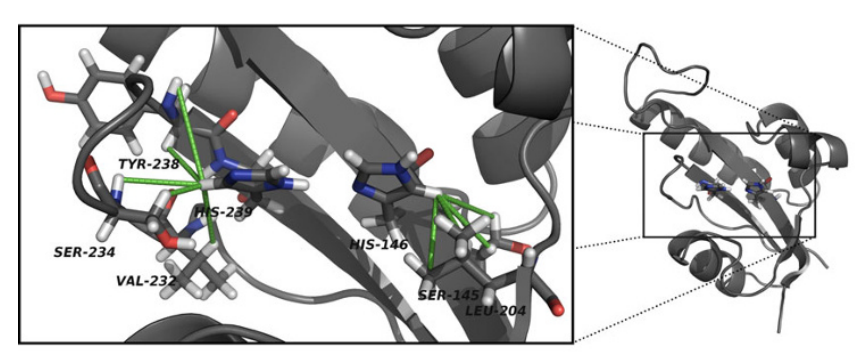

\section{Figure 5}

Detailed structure of the S. aureus PrsA-PPlase active site histidines. The most important NOE distance constraints determining the orientation of the active site histidine ring planes are indicated with green lines. This conformation of the histidines enables hydrogen bonding between

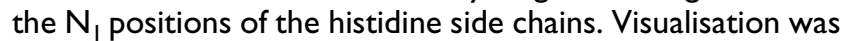
created using PyMol [34]. strate binding when the substrate contains a negatively charged glutamate residue before the processed proline.

Referring to previously published NMR titration data, Bailey et al. concluded recently that parvulin active site histidines are not involved in substrate binding [23]. It should be noted, however, that NMR chemical shift perturbation studies are commonly done using only backbone $\mathrm{N}-\mathrm{H}$ correlations (i.e. using ${ }^{1} \mathrm{H}-{ }^{15} \mathrm{~N}-\mathrm{HSQC}$ spectrum). Participation of the active site histidines (H146 and H239) in the substrate binding is not easily observed in ${ }^{1} \mathrm{H}-{ }^{15} \mathrm{~N}$ HSQC-based NMR titrations since backbone amides reside quite far from the peptide binding site. Involvement of the histidine side chains in substrate binding is however clearly evidenced by the chemical shift perturbations in the ${ }^{1} \mathrm{H}-{ }^{13} \mathrm{C}-\mathrm{HSQC}$ spectrum of the aromatic residues (see Figure 3 ).

A plot of generalized order parameters $\mathrm{S}^{2}$ as function of sequence demonstrates a tightly folded protein (Figure $7 a)$. Reduced $S^{2}$ values at the $S_{1}-H_{1}$ loop indicate that the loop is more flexible than the rest of the structure. Conformational variation of the structure family at the $\mathrm{S}_{1}-\mathrm{H}_{1}$ loop is thus an indication of real dynamic behaviour, not solely a lack of NOE distance restraints (Figure 9). This flexibility enables induced fit mechanism during binding of negatively charged substrate peptides. Especially interesting is the rather low $\mathrm{S}^{2}$ of T195. This threonine also stands out in the amide proton exchange rate plot with a high exchange rate (Figure $7 \mathrm{c}$ ). Order parameter of the solvent exposed T195 might be distorted due to chemical exchange of the amide proton with water. Presence of peptide substrate (Suc-AEPF-pNA) induces some changes in the order parameters and exchange rates (Figure $7 b-c$ ). Most of the changes are, as expected, at the loops surrounding the active site and carrying the catalytic residues. However, somewhat unexpected changes are observed in the helix $\mathrm{H}_{1}$ which is rather distant from the peptide binding site. Since the relaxation experiments were conducted in presence of Suc-AEPF-pNA peptide, which has a negatively charged residue before the proline, the changes in $\mathrm{S}^{2}$ values for the $\mathrm{H}_{1}$ helix might be due to rearrangement of the $\mathrm{S}_{1}-\mathrm{H}_{1}$ loop during peptide binding. The $\mathrm{S}_{1}-\mathrm{H}_{1}$ loop can be acting as a hinge twisting the $\mathrm{H}_{1}$ helix.

Tautomeric state of the active site histidine residues was determined using NMR spectroscopy (Figure 3). The active site histidines are highly conserved in all parvulin PPIases. There is a systematic discrepancy regarding the conformation of these histidines between the crystal structures and the solution structures [5-12]. In the crystal structures the histidine side chain $\mathrm{N}_{1}$ nitrogens point to opposite directions whereas in the solution structures they face each other (Figures 10a-b). The ring planes of both histidines are flipped $180^{\circ}$ changing the exact location of the ring nitrogens. The NOE distance restraints 

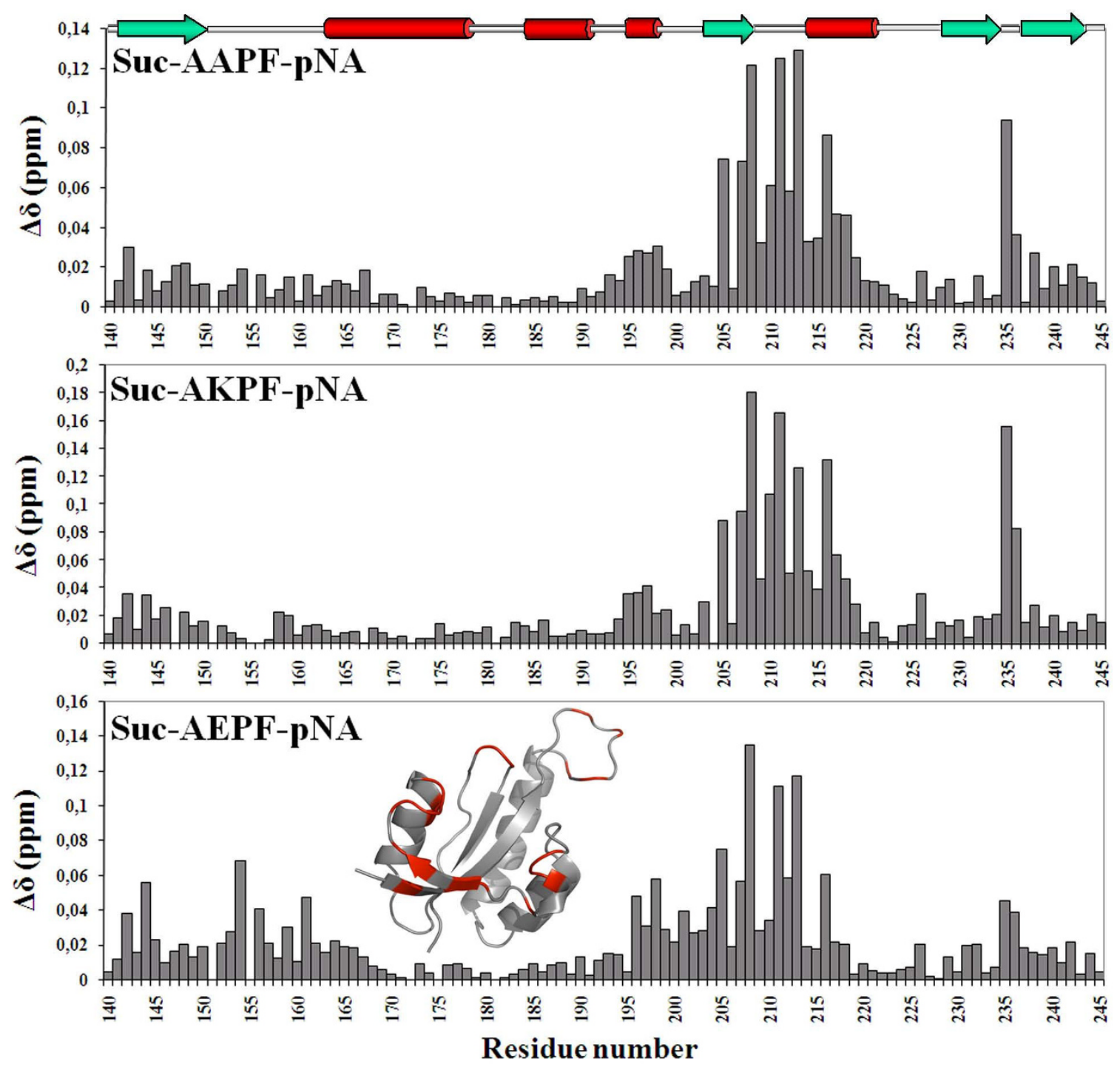

\section{Figure 6}

Chemical shift mapping of PrsA-PPlase during Suc-AXPF-pNA titrations. Chemical shift perturbations induced to the backbone amide signals of $S$. aureus PrsA-PPlase upon Suc-AXPF-pNA $(X=A, K$ or $E)$ peptide titration. Position of the secondary structure elements in the sequence is shown at the top of the graph: green arrow $-\beta$-strand, red bar $-\alpha$-helix. Structure insert shows the location of residues which evinced the largest chemical shift perturbations in the Suc-AEPF-pNA titration (red $-\Delta \delta>0.03$ ppm).

define the orientation seen in the NMR structures unambiguously (Figure 5). This difference is crucial regarding the discussion on the catalysis mechanism. The original hypothesis of the catalysis mechanism of parvulin PPIases was made based on the crystal structure of hPin 1 [5]. Changing the orientation of the histidine ring planes affects the location of the transferable protons of the imidazole moieties. Using NMR spectroscopy we were also able to determine the tautomeric state of the histidines: in S. aureus PrsA-PPIase $\mathrm{H} 146$ is $\mathrm{N}_{3}$-protonated and $\mathrm{H} 239$ is $\mathrm{N}_{1}$-protonated (Figure 3 ). This combination of tautomeric states enables hydrogen bonding between the $\mathrm{N}_{1}$ nitrogens of the two histidines and it also creates prerequisites for a charge relay system through the active site of the enzyme (Figure 10c) [25]. The role of the parvulin active site histidines was recently discussed in detail by Bailey et al. [23]. Using a thorough array of active site histidine mutants of hPin 1 they showed that the histidines are not essential for the catalytic activity of hPin 1 but rather have a structural role and impact on the stability of the PPIase domain. It was noted that the capability of these residues to form hydrogen bonds is not an absolute requirement for proper enzyme function and that the double-mutant H59L/H157L even exhibited surprisingly 

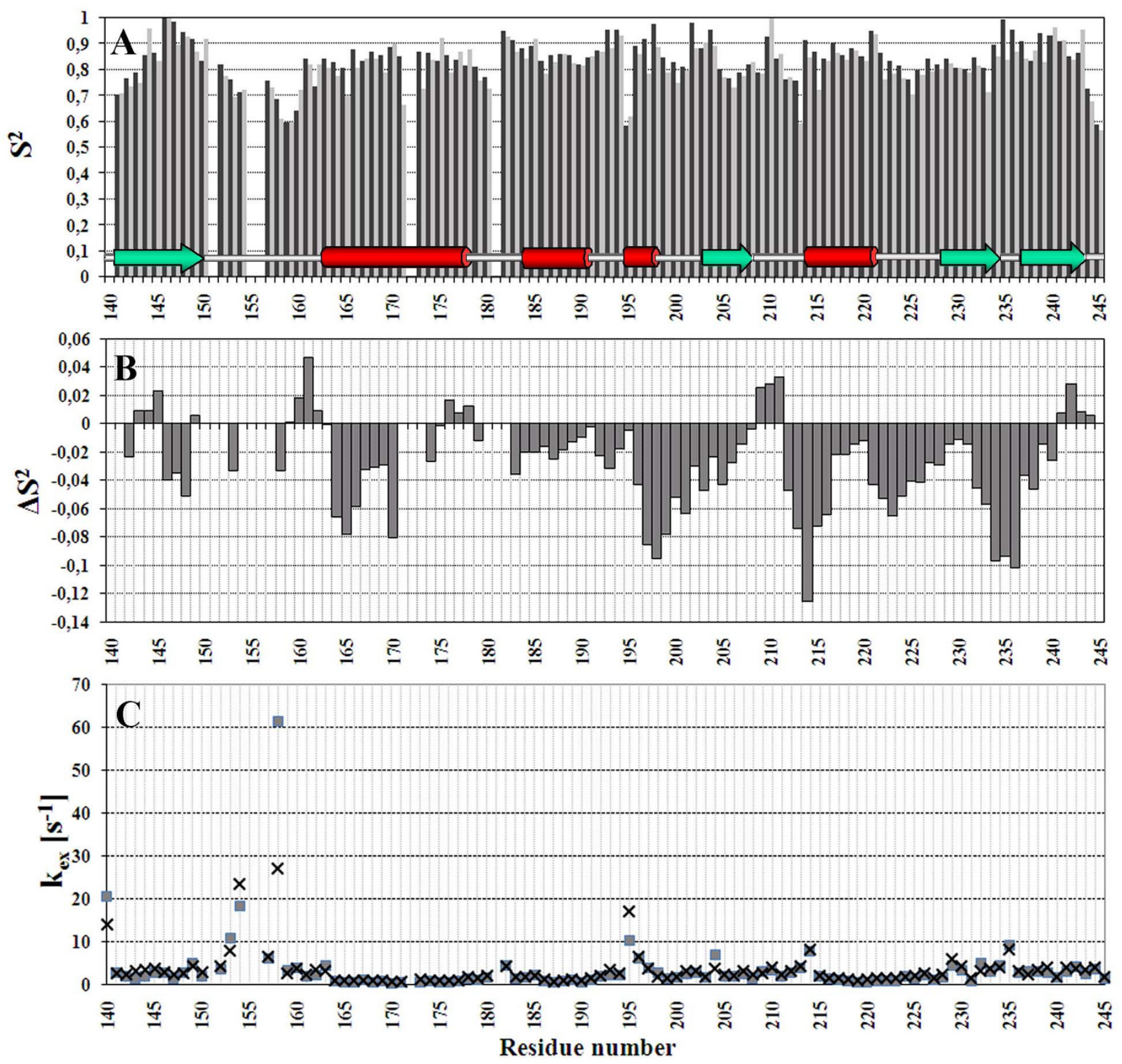

\section{Figure 7}

Dynamical features of S. aureus PrsA-PPlase. Generalized order parameters $\left(\mathrm{S}^{2}\right)$ for backbone amides were calculated using ModelFree formalism from ${ }^{15} \mathrm{~N} \mathrm{R}_{1}$ and $\mathrm{R}_{2}$ relaxation rates and $1 \mathrm{H}-{ }^{15} \mathrm{~N}$ heteronuclear $\mathrm{NOEs}$. (A) Generalized order parameter $\left(\mathrm{S}^{2}\right)$ as function of residue sequence for PrsA-PPlase (dark grey) and for PrsA-PPlase + Suc-AEPF-pNA (light grey). (B) $S^{2}$ changes induced upon Suc-AEPF-pNA peptide addition averaged over three consecutive residues. (C) Backbone amide proton exchange rates as function of residue sequence for PrsA-PPlase (box) and PrsA-PPlase + Suc-AEPF-pNA (cross). Position of the secondary structure elements in the sequence is shown on the top panel: green arrow $-\beta$-strand; red bar - $\alpha$-helix.

high activity. The double-mutant was regarded to enhance the integrity of the catalytic site and the stability of the enzyme through additional hydrophobic contacts in the protein core. The hydrogen bonding between the active site histidines might also be a way to stabilise the parvulin fold. When this interaction is interrupted by single histi- dine mutation the stabilisation is lost but the doublemutant, even through a different mechanism (i.e. hydrophobic contacts), restores some of the stabilisation. Whether the histidines actively participate in the catalysis or solely serve as structural support for the catalytic machinery remains to be confirmed. 

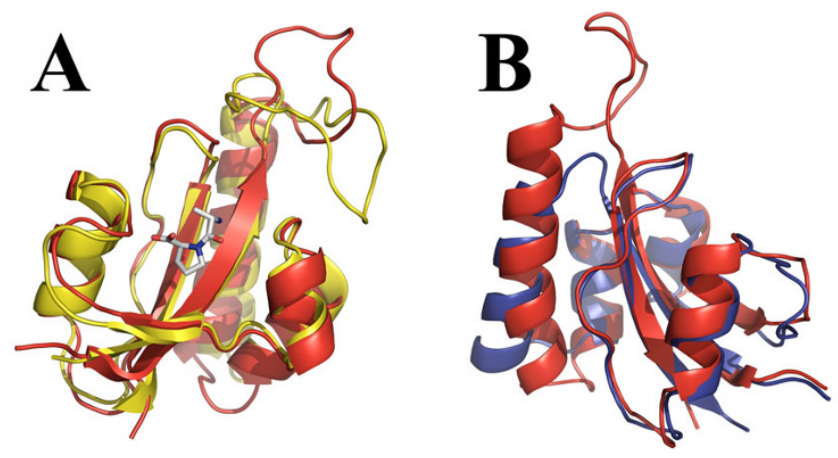

Figure 8

Comparison of $S$. aureus PrsA-PPlase structure to hPin I and B. subtilis PrsA. Superimposition of the $S$. aureus PrsA-PPlase (red) (A) with the crystal structure of hPin I complexed with AlaPro dipeptide (yellow) [PDB:IPIN] [5] and (B) with the solution structure of PrsA-PPlase from B. subtilis (blue) [PDB:IZK6][12]. Note that the two structure overlays are presented from different perspectives to highlight the differences of the two structures. Structure superimpositions and visualisations were done using PyMol [34].

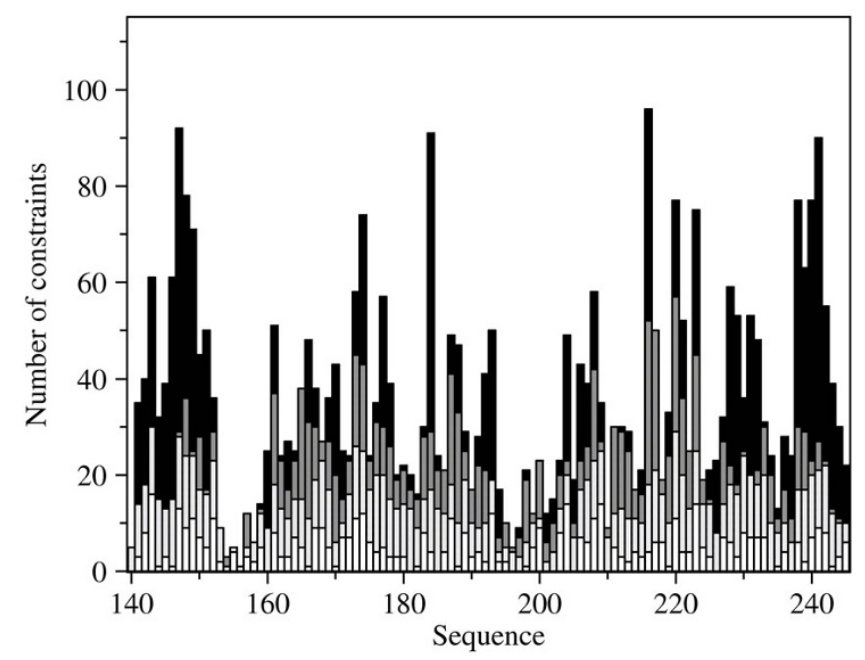

Figure 9

Sequential distribution of the NOE distance constraints used in the structure calculation. The NOE distance constraints have been classified according to their range $(R)$ as: Black - long-range $(R \geq 5)$; dark grey - mediumrange $(5>R>1)$; grey - sequential $(R=1)$; white - intraresidual $(R=0)$. Graph was created with CYANA 2.I [14].

The original parvulin catalysis mechanism presented by Ranganathan et al. [5] has been disproved [21-23]. Comparison of the active site structure of $S$. aureus PrsA-PPIase and other parvulin PPIases questions the residues proposed to be responsible for the catalysis in parvulins [5]. The cysteine residue $\mathrm{C} 113$ of hPin 1 was originally claimed to act as a nucleophile starting the catalysis (Figure 10b).

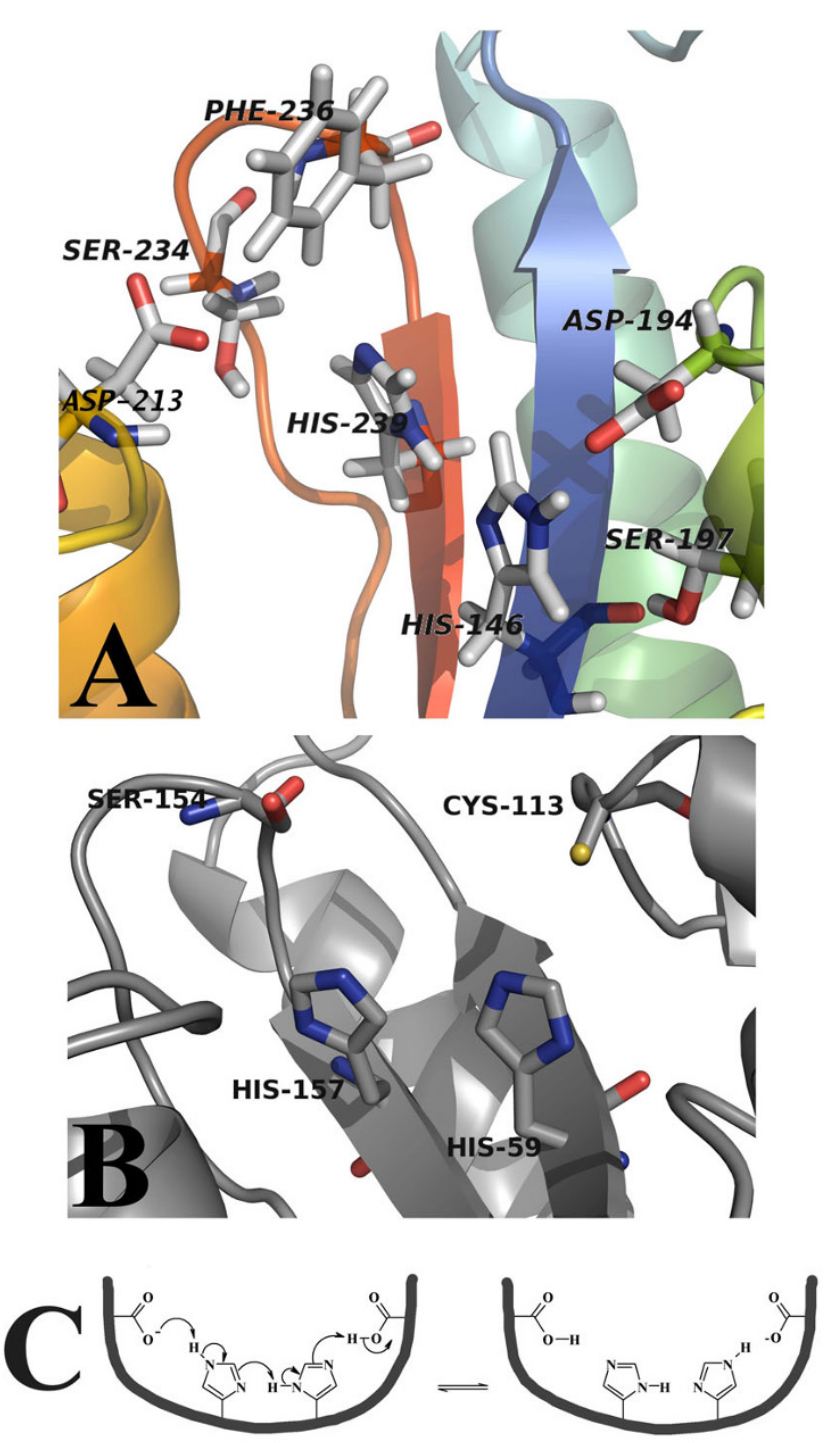

Figure 10

The differences between the active site residues of parvulins. Comparison of PrsA-PPlase and hPin I active site residues shows that the highly conserved histidine sidechains have distinct conformations. (A) The active site residues of S. aureus PrsA-PPlase. (B) The hPin I residues [PDB:IPIN] proposed to participate in the catalysis mechanism. (C) Schematic presentation of the potential charge relay system of S. aureus PrsA-PPlase. Deprotonation of the active site aspartates can be promoted by delocalisation of the negative charge through the active site histidines. Protein structure visualisations were done using PyMol [34].

This residue is replaced in S. aureus and in B. subtilis PrsAs by an aspartate (D194 and D154, respectively) which is also a potential nucleophile. In fact, Behrsin et al. have proved that the Pin1 C113D mutant remains functional [21]. Forthcoming steps of the original catalysis mechanism [5] include participation of a serine residue (S154 of hPin1) acting as a proton donor. In S. aureus PrsA-PPIase 
this residue is replaced by phenylalanine (F236) which is not capable of carrying out protonation/deprotonation steps. The same situation is also faced with other parvulin PPIases e.g. E. coli Par10 [9] and hPar14 [7]. In some parvulin PPIases this residue is replaced by valine and for example in B. subtilis PrsA by tyrosine [12]. Evidently the original catalysis mechanism proposed based on the crystal structure of hPin 1 cannot be a universal route of the reaction for all parvulins. A closer inspection of the active site of $S$. aureus PrsA-PPIase reveals a somewhat symmetric assembly of aspartate and serine residues on both sides of the histidine pair (Figure 10a). Similar set of residues is also found in B. subtilis PrsA [12]. Mutation studies of $B$. subtilis PrsA have shown that D154A substitution (corresponding to D194 in S. aureus PrsA) destroys only half of the catalytic activity of PrsA [2]. Obviously some other residue can perform the role of the nucleophilic residue when it is inactivated by mutation. The symmetrical assembly of aspartates and serines and the charge relay system through the active site histidines would imply a protonation/deprotonation step as part of the catalytic mechanism. The charge relay system (Figure 10c) could facilitate deprotonation of the aspartates which would enhance their nucleophilic character. In light of the diverse structural and functional data on parvulin PPIases one inevitably raises a question whether all parvulin PPIases even share the same catalysis mechanism.

\section{Conclusion}

The solution structure of PrsA-PPIase from S. aureus enables detailed study of its function and target based design of inhibitors. Highly conserved protein sequences are also found in other Staphylococcus subspecies. Exact biological role and importance of PrsA are still unclear although it is known to act as a foldase of secreted proteins (e.g. bacterial toxins) [3] and it is shown to be essential for B. subtilis [2]. Natural substrates of $S$. aureus PrsA-PPIase are not known at present, but the enzyme may prefer substrates where a negatively charged residue precedes the processed proline. The structure of the catalytic site of $S$. aureus PrsAPPIase conflicts with the original hypothetical catalysis mechanism of parvulin PPIases. Recent studies also recognize the deficiencies of the parvulin catalysis mechanism [21-23]. The orientation and the tautomeric state of the active site histidine residues of $S$. aureus PrsA-PPIase suggest that the catalytic mechanism includes a protonation/ deprotonation step facilitated by a charge relay system through the active site histidine pair. On the other hand, the hydrogen bonding between the active site histidines might merely serve as a structural stabilisation mechanism of the enzyme fold. Apparently the catalysis mechanism of parvulin-type PPIases still needs some clarifications. Existing structural data on parvulins can be used to design further experiments, e.g. site-directed mutagenesis, to decipher the detailed catalysis mechanism.

\section{Methods}

\section{Protein expression and purification}

The PPIase domain (residues 140-245) was expressed as glutathione S-transferase (GST) fusion. The protein was overexpressed in E. coli BL21 strain containing the pGEX$2 \mathrm{~T}$ expression vector (GE Healthcare). For enzymatic studies, the cells were grown and harvested as described earlier [2]. For NMR samples, the cells were grown in M9 medium containing either ${ }^{15} \mathrm{NH}_{4} \mathrm{Cl}$ as the sole nitrogen source or $\left[{ }^{13} \mathrm{C}_{6}\right]$-D-glucose $/{ }^{15} \mathrm{NH}_{4} \mathrm{Cl}$ as the sole carbon and nitrogen sources, respectively. The expression of protein was induced by addition of $1 \mathrm{mM}$ isopropyl- $\beta$-D-thiogalactopyranoside (IPTG) at $\mathrm{A}_{600}$ of 0.8 . The cells were grown 4 additional hours and harvested. For both enzymatic and NMR studies the cells were broken by French Press and centrifuged. The supernatant was applied to a glutathione-Sepharose FF (GE Healthcare) column, and washed with phosphate-buffered saline (PBS). The precission protease was added to the column and incubated $4 \mathrm{~h}$ at $+5{ }^{\circ} \mathrm{C}$ to release the protein. The cleaved protein was eluted with PBS, and the fractions containing the protein were concentrated with Vivaspin 2 (Sartorius Stedim Biotech). For NMR samples, the buffer was changed to 20 $\mathrm{mM}$ Bis-Tris $\mathrm{pH} 6.8$, and $\mathrm{D}_{2} \mathrm{O}$ was added to the final concentration of $8 \%(\mathrm{v} / \mathrm{v})$. The final protein concentration was $\sim 1 \mathrm{mM}$.

\section{Protease-coupled PPlase assay}

Prolyl isomerase activity of PrsA-PPIase was determined with $\alpha$-chymotrypsin-coupled PPIase assay as described by Fischer $e$ al. [26]. The catalytic activity was tested with synthetic succinyl-AXPF-p-nitroanilide (Suc-AXPF-pNA) peptides where $\mathrm{X}$ is alanine $(\mathrm{A})$, lysine $(\mathrm{K})$, asparagine $(\mathrm{N})$, glutamic acid (E), phosphoserine $(\mathrm{pS})$ or phosphothreonine ( $\mathrm{pT}$ ). The peptides with $\mathrm{A}, \mathrm{K}$ and $\mathrm{E}$ were purchased from Bachem (Bubendorf, Switzerland). SucANPF- $p$ NA was synthesized by Ale Närvänen in University of Kuopio, Finland. The phosphorylated peptides were purchased from EZBiolab Inc. (Westfield, IN). p-Nitroanilide was cleaved off by $\alpha$-chymotrypsin and the increase of released $p$-nitroanilide was monitored in absorbance at $390 \mathrm{~nm}$. Cyclophilin from calf thymus (Sigma-Aldrich) was used as a positive control.

\section{Structure determination}

NMR spectroscopy for the structure determination was performed on Varian INOVA $600 \mathrm{MHz}$ and $800 \mathrm{MHz}$ spectrometers with $5 \mathrm{~mm}$ inverse z-gradient triple-resonance probe heads at $25^{\circ} \mathrm{C}$. The acquisition and processing were conducted with VNMR 6.1C software (Varian Inc., Palo Alto, CA). A conventional set of three-dimensional triple resonance experiments i.e. iHNCA [27], HN(CO)CA, HNCACB, HN(CO)CACB, HNCO, $\mathrm{HN}(\mathrm{CA}) \mathrm{CO}[28,29]$ was recorded for sequential backbone assignment. The aliphatic side chain resonances were assigned using three-dimensional $\mathrm{HCCH}-\mathrm{COSY}$ and 
HCCH-TOCSY experiments with the help of CC(CO)NH and $\mathrm{HCC}(\mathrm{CO}) \mathrm{HN}$ experiments [28]. $(\mathrm{H} \beta) \mathrm{C} \beta(\mathrm{C} \gamma \mathrm{C} \delta) \mathrm{H} \delta$, $(\mathrm{H} \beta) \mathrm{C} \beta(\mathrm{C} \gamma \mathrm{C} \delta \mathrm{C} \varepsilon) \mathrm{H} \varepsilon$ [30] experiments and ${ }^{13} \mathrm{C}$-edited three-dimensional HSQC-NOESY spectrum were used in assignment of aromatic side chain resonances. Sparky 3.110 program [31] was used to analyze the NMR spectra.

The distance restraints for structure calculation were extracted from signal intensities of ${ }^{15} \mathrm{~N}$ - and ${ }^{13} \mathrm{C}$-edited three-dimensional HSQC-NOESY spectra. Automated NOESY signal assignment and structure calculation was conducted with CYANA 2.1 software [14]. In addition to NOE derived distance restraints, $146 \phi$ and $\psi$ dihedral angle constraints (average of the TALOS database hits used in the prediction $\pm 2 \mathrm{SD}$ ) were generated from chemical shift data with TALOS program (version 2003.027.13.05) [32]. After torsion angle dynamics run 40 structures were chosen from 400 calculated structures based on lowest target function value. These 40 structures were refined with molecular dynamics using Born implicit solvent model in AMBER 8.0 [15]. The final ensemble of 25 structures was chosen based on lowest AMBER energy and restraint violation energy. Quality of the final structures was analyzed with PROCHECK-NMR [16] and WHAT_CHECK [17] programs. Tautomeric state of the active site histidines H146 and $\mathrm{H} 239$ was determined using $\mathrm{J}_{\mathrm{CN}}$ intensity modulated constant time ${ }^{1} \mathrm{H}-{ }^{13} \mathrm{C}-\mathrm{HSQC}$ spectrum [18] both in presence and in absence of the substrate peptide Suc-AEPF-pNA. Molecule visualization programs MOLMOL [33] and PyMOL [34] were used in preparation of the figures representing the protein structure.

\section{Peptide titrations}

The Suc-AXPF- $p$ NA tetrapeptides, where $\mathrm{X}=\mathrm{A}$, K or E, were tested for binding to PrsA-PPIase. The ${ }^{1} \mathrm{H}-{ }^{15} \mathrm{~N}-\mathrm{HSQC}-$ based titration experiments were conducted with $0.3 \mathrm{mM}$ ${ }^{15} \mathrm{~N}$-labeled PrsA-PPIase samples adding the unlabeled peptide as concentrated solution in sample buffer. The ${ }^{1} \mathrm{H}-{ }^{15} \mathrm{~N}-\mathrm{HSQC}$ spectrum was recorded after each peptide addition. Large excess of peptide was used at the last titration point to obtain high proportion of ligand-bound form of the protein. Total chemical shift change of the backbone amide signals at the titration end-point was calculated with the equation $\Delta \delta=\left[\left(0.17^{*} \Delta \delta_{\mathrm{N}}\right)^{2}+\left(\Delta \delta_{\mathrm{H}}\right)^{2}\right]^{1 / 2}$. Determination of ${ }^{15} \mathrm{~N}$ relaxation rates, heteronuclear NOEs, amide proton exchange rates and tautomeric state of the histidine side chains in presence of Suc-AEPF- $p$ NA peptide substrate were done at the titration end point (20fold excess of peptide to protein).

\section{Protein dynamics}

${ }^{15} \mathrm{~N} \mathrm{R}_{1}$ and $\mathrm{R}_{2}$ relaxation rates of the backbone amide groups were measured using three-dimensional relaxation rate-resolved ${ }^{1} \mathrm{H}-{ }^{15} \mathrm{~N}-\mathrm{HSQC}$ spectra $[35,36]$. Inverse Laplace transform was applied to the relaxation dimension enabling extraction of the relaxation rate constants simply by peak picking. Heteronuclear NOEs of the backbone amide nitrogens were determined with conventional methods [37]. The data for the analysis of protein dynamics was recorded with a Bruker DRX $500 \mathrm{MHz}$ spectrometer equipped with a $5 \mathrm{~mm}$ z-gradient inverse broadband probehead from $0.3 \mathrm{mM}$ 15N-labeled PrsA-PPIase sample. Generalized order parameters for each backbone amide were extracted from the relaxation data using Modelfree 4.1 program [38,39] with FASTModelfree interface [40]. Proton exchange rates between backbone amides and water were measured through exchange rate-resolved ${ }^{1} \mathrm{H}-{ }^{15} \mathrm{~N}-\mathrm{HSQC}$ spectrum [41]. Relaxation and exchange rates as well as heteronuclear NOEs were determined both in absence and in presence of substrate peptide Suc-AEPF$p$ NA.

\section{Data deposition}

The resonance assignments of $S$. aureus PrsA-PPIase and the distance constraints used in structure calculation have been deposited in BioMagResBank under accession number 15628. The atomic coordinates of $S$. aureus PrsAPPIase structure ensemble have been deposited in Protein Data Bank under accession code 2JZV.

\section{Authors' contributions}

OH carried out the NMR structure determination, peptide titrations, analyzed the NMR relaxation data and wrote the manuscript. RS prepared all protein samples used in the study, carried out the protease-coupled PPIase assays, participated in the design of the study and wrote the manuscript. HT conducted peptide titrations. $\mathrm{SH}$ and $\mathrm{HK}$ recorded and processed the NMR relaxation and exchange data. PP recorded the NMR spectra for structure determination, participated in the design of the study and wrote the manuscript. IK participated in the design of the study and wrote the manuscript. All authors read and approved the final manuscript.

\section{Acknowledgements}

This work was supported by The Finnish Academy (grant no. I233 I 8 to IK), Sigrid Juselius Foundation (to PP \& IK), and Helsinki University's Research Funds (to PP). We thank Tuula Lunden, Ph.D., for preparation of chromosomal DNA from S. aureus and Anne Hakonen for excellent technical assistance.

\section{References}

I. Kuroda M, Ohta T, Uchiyama I, Baba T, Yuzawa H, Kobayashi I, Cui L, Oguchi A, Aoki K, Nagai Y, Lian J, Ito T, Kanamori M, Matsumaru H, Maruyama A, Murakami H, Hosoyama A, Mizutani-Ui Y, Takahashi NK, Sawano T, Inoue R, Kaito C, Sekimizu K, Hirakawa H, Kuhara S, Goto S, Yabuzaki J, Kanehisa M, Yamashita A, Oshima K, Furuya K, Yoshino C, Shiba T, Hattori M, Ogasawara N, Hayashi H, Hiramatsu K: Whole genome sequencing of meticillin-resistant Staphylococcus aureus. Lancet 200 I, 357:1225-1240.

2. Vitikainen M, Lappalainen I, Seppala R, Antelmann H, Boer H, Taira S, Savilahti H, Hecker M, Vihinen M, Sarvas M, Kontinen VP: Structurefunction analysis of PrsA reveals roles for the parvulin-like and flanking $\mathbf{N}$ - and $\mathbf{C}$-terminal domains in protein folding and secretion in Bacillus subtilis. I Biol Chem 2004, 279: 19302-19314. 
3. Sarvas M, Harwood CR, Bron S, van Dijl JM: Post-translocational folding of secretory proteins in Gram-positive bacteria. Biochim Biophys Acta 2004, I 694:3 I I-327.

4. Fanghänel J, Fischer G: Insights into the catalytic mechanism of peptidyl prolyl cis/trans isomerases. Front Biosci 2004, 9:3453-3478.

5. Ranganathan R, Lu KP, Hunter T, Noel JP: Structural and functional analysis of the mitotic rotamase Pin I suggests substrate recognition is phosphorylation dependent. Cell 1997, 89:875-886

6. Bayer E, Goettsch S, Mueller JW, Griewel B, Guiberman E, Mayr LM, Bayer P: Structural analysis of the mitotic regulator $\mathbf{h P i n} I$ in solution. Insights into domain architecture and substrate binding. J Biol Chem 2003, 278:26183-26193.

7. Sekerina E, Rahfeld JU, Muller J, Fanghanel J, Rascher C, Fischer G Bayer P: NMR solution structure of hPar 14 reveals similarity to the peptidyl prolyl cis/trans isomerase domain of the mitotic regulator $\mathrm{hPin} I$ but indicates a different functionality of the protein. J Mol Biol 2000, 30 I:I003-1017.

8. Landrieu I, Wieruszeski JM, Wintjens R, Inze D, Lippens G: Solution structure of the single-domain prolyl cis/trans isomerase PIN I At from Arabidopsis thaliana. J Mol Biol 2002, 320:32 I-332.

9. Kuehlewein A, Voll G, Alvarez BH, Kessler H, Fischer G, Rahfeld JU, Gemmecker G: Solution structure of Escherichia coli Parl 0: The prototypic member of the Parvulin family of peptidylprolyl cis/trans isomerases. Protein Sci 2004, I 3:2378-2387.

10. Bitto E, McKay DB: Crystallographic structure of SurA, a molecular chaperone that facilitates folding of outer membrane porins. Structure 2002, 10:1489-1498.

II. Li Z, Li H, Devasahayam G, Gemmill T, Chaturvedi V, Hanes SD, Van Roey P: The structure of the Candida albicans Ess I prolyl isomerase reveals a well-ordered linker that restricts domain mobility. Biochemistry 2005, 44:6180-6189.

12. Tossavainen H, Permi P, Purhonen SL, Sarvas M, Kilpeläinen I, Seppala $R:$ NMR solution structure and characterization of substrate binding site of the PPlase domain of PrsA protein from Bacillus subtilis. FEBS Lett 2006, 580:|822-1826.

13. Hodak H, Wohlkönig A, Smet-Nocca C, Drobecq H, Wieruszeski JM, Sénéchal M, Landrieu I, Locht C, Jamin M, Jacob-Dubuisson F: The peptidyl-prolyl isomerase and chaperone Par27 of Bordetella pertussis as the prototype for a new group of parvulins. $J \mathrm{Mol}$ Biol 2008, 376:4|4-426.

14. Herrmann T, Güntert P, Wüthrich K: Protein NMR structure determination with automated NOE assignment using the new software CANDID and the torsion angle dynamics algorithm DYANA. J Mol Biol 2002, 3 I 9:209-227.

15. Case DA, Darden TA, Cheatham TE III, Simmerling CL, Wang J, Duke RE, Luo R, Merz KM, Wang B, Pearlman DA, Crowley M, Brozell S Tsui V, Gohlke H, Mongan J, Hornak V, Cui G, Beroza P, Schafmeister C, Caldwell JW, Ross WS, Kollman PA: AMBER 8. University of California, San Francisco, CA; 2004

16. Laskowski RA, Rullmann JAC, MacArthur MW, Kaptein R, Thornton JM: AQUA and PROCHECK-NMR: Programs for checking the quality of protein structures solved by NMR. J Biomol NMR 1996, 8:477-486.

17. Hooft RWW, Vriend G, Sander C, Abola EE: Errors in protein structures. Nature 1996, 38 I:272-272.

18. Shimba N, Takahashi H, Sakakura M, Fujii I, Shimada I: Determination of protonation and deprotonation and tautomeric states of histidine residues in large proteins using nitrogencarbon J couplings in imidazole ring. J Am Chem Soc 1998 1 20:10988-10989.

19. Sudmeier JL, Bradshaw M, Coffman Haddad KE, Day RM, Thalhauser C), Bullock PA, Bachovchin WW: Identification of histidine tautomers in proteins by $2 \mathrm{D}{ }^{1} \mathrm{H} /{ }^{13} \mathrm{C}^{\delta 2}$ one-bond correlated NMR. J Am Chem Soc 2003, I 25:8430-843I.

20. Rahfeld J-U, Schierhornb A, Mannc K, Fischer G: A novel peptidylprolyl cis/trans isomerase from Escherichia coli. FEBS Lett 1994, 343:65-69.

21. Behrsin CD, Bailey ML, Bateman KS, Hamilton KS, Wahl LM, Brand C], Shilton BH, Litchfield DW: Functionally important residues in the peptidyl-prolyl isomerase Pin I revealed by unigenic evolution. J Mol Biol 2007, 365: I |43-I I62.

22. Lippens G, Landrieu I, Smet C: Molecular mechanisms of the phospho-dependent prolyl cis/trans isomerase Pin I. FEBS 2007, 274:521।-5222.
23. Bailey ML, Shilton BH, Brand CJ, Litchfield DW: The dual histidine motif in the active site of Pin I has a structural rather than catalytic role. Biochemistry 2008, 47: I | 48 I- I | 489.

24. Holm L, Sander C: Protein structure comparison by alignment of distance matrices. J Mol Biol 1993, 233:I23-I38.

25. Blow DM, Birktoft J, Hartley BS: Role of a buried acid group in the mechanism of action of chymotrypsin. Nature 1969, 221 :337-340

26. Fischer G, Bang H, Ludwig B, Mann K, Hacker J: Mip protein of Legionella pneumophila exhibits peptidyl-prolyl-cis/trans isomerase (PPlase) activity. Mol Microbiol 1992, 6: I 375-I383.

27. Permi P: Intraresidual HNCA: An experiment for correlating only intraresidual backbone resonances. J Biomol NMR 2002, 23:201-209.

28. Sattler M, Schleucher J, Griesinger C: Heteronuclear multidimensional NMR experiments for the structure determination of proteins in solution employing pulsed field gradients. Prog Nucl Magn Res Spectros 1999, 34:93-I58.

29. Permi P, Annila A: Coherence transfer in proteins. Prog Nucl Magn Res Spectros 2004, 44:97-I 37.

30. Yamazaki T, Forman-Kay JD, Kay LE: Two-dimensional NMR experiments for correlating ${ }^{13} \mathbf{C} \beta$ and ${ }^{1} \mathrm{H} \delta / \varepsilon$ chemical shifts of aromatic residues in $13 \mathrm{C}$-labeled proteins via scalar couplings. J Am Chem Soc 1993, I I 5: I I 054-I I 055.

31. Goddard TD, Kneller DG: Sparky 3. University of California, San Francisco, CA; 2004.

32. Cornilescu G, Delaglio F, Bax A: Protein backbone angle restraints from searching a database for chemical shift and sequence homology. J Biomol NMR 1999, I 3:289-302.

33. Koradi R, Billeter M, Wüthrich K: MOLMOL: A program for display and analysis of macromolecular structures. I Mol Graph 1996, | 4:5|-55.

34. DeLano WL: The PyMOL Molecular Graphics System. DeLano Scientific, Palo Alto, CA, USA; 2002.

35. Heikkinen S, Kilpeläinen I: Linewidth-resolved ${ }^{15}$ N HSQC, a simple 3D method to measure ${ }^{15} \mathrm{~N}$ relaxation times from $T_{1}$ and $\mathbf{T}_{2}$ linewidths. J Magn Reson 200I, I5 I:3 |4-319.

36. Koskela $\mathrm{H}$, Kilpeläinen I, Heikkinen S: Evaluation of protein ${ }^{15} \mathbf{N}$ relaxation times by inverse Laplace transformation. Magn Reson Chem 2004, 42:6I-65.

37. Farrow NA, Muhandiram R, Singer AU, Pascal SM, Kay CM, Gish G, Shoelson SE, Pawson T, Forman-Kay JD, Kay LE: Backbone dynamics of a free and a phosphopeptide-complexed Src homology 2 domain studied by ${ }^{15} \mathbf{N}$ NMR relaxation. Biochemistry 1994 , 33:5984-6003.

38. Mandel AM, Akke M, Palmer AG: Backbone dynamics of Escherichia coli ribonuclease $\mathrm{HI}$ : Correlations with structure and function in an active enzyme. I Mol Biol 1995, 246: | 44- I63.

39. Palmer AG, Rance $M$, Wright PE: Intramolecular motions of a zinc finger DNA-binding domain from $X$ fin characterized by proton-detected natural abundance ${ }^{13} \mathrm{C}$ heteronuclear NMR spectroscopy. J Am Chem Soc I 99I, I I 3:437 I-4380.

40. Cole R, Loria JP: FAST-Modelfree: a program for rapid automated analysis of solution NMR spin-relaxation data. J Biomol NMR 2003, 26:203-213

4I. Koskela H, Heikkinen O, Kilpeläinen I, Heikkinen S: Rapid and accurate processing method for amide proton exchange rate measurement in proteins. J Biomol NMR 2007, 37:313-320.

Publish with Biomed Central and every scientist can read your work free of charge

"BioMed Central will be the most significant development for disseminating the results of biomedical research in our lifetime. "

Sir Paul Nurse, Cancer Research UK

Your research papers will be:

- available free of charge to the entire biomedical community

- peer reviewed and published immediately upon acceptance

- cited in PubMed and archived on PubMed Centra

- yours - you keep the copyright 